\title{
Hypertension in a Population of Active Duty Service Members
}

Brian A. Smoley, MD, MPH, Nicholas L. Smith, PhD, and Guy P. Runkle, MD, MA

Background: Hypertension is a common condition, but little is known about its prevalence in the Armed Forces. Our purpose was to provide an estimate of the prevalence of hypertension in a large population of US service members.

Methods: We reviewed the screening records for service members who completed health risk assessments at Fort Lewis in Tacoma, WA, in 2004. The prevalence of hypertension and prehypertension were estimated from single recorded blood pressure readings and subjects' reported use of blood pressure medications. Study subject characteristics associated with hypertension and prehypertension were examined by $\chi^{2}$ tests and multivariate logistic regression.

Results: Thirteen percent of the 15,391 subjects met the study definition for hypertension; $62 \%$ met the study definition for prehypertension. Increasing age and body mass index, male sex, black race/ ethnicity, and senior rank were associated with hypertension; only body mass index, male sex, and senior rank were associated with prehypertension.

Conclusion: Hypertension and prehypertension are more prevalent in the US Armed Forces than has been previously reported, and prehypertension may be more common in the US Armed forces than in the general population. The high prevalence of prehypertension found in this young, fit population suggests a need to better define the risks and benefits associated with the diagnosis and treatment of prehypertension in low-risk populations. (J Am Board Fam Med 2008;21:504-11.)

Hypertension is a very common condition that affects $27 \%$ of adult Americans. It is particularly common in older populations (prevalence of $65 \%$ in those 60 years of age and older), but less com-

This article was externally peer reviewed.

Submitted 5 August 2007; revised 8 May 2008; accepted 12 May 2008.

From the Puget Sound Family Medicine Residency, Naval Hospital Bremerton, Bremerton, Washington (BAS); Department of Epidemiology, University of Washington and the Seattle Epidemiologic Research and Information Center of the Department of Veterans Affairs Office of Research and Development (NLS); and the United Family Medicine Residency Program, Saint Paul, MN (GPR).

Funding: none.

Conflict of interest: none declared.

Disclaimer: The views expressed in this work are those of the author(s) and do not necessarily reflect the official policy or position of the Department of the Navy, Department of the Army, Department of Defense, or the US government. The investigator(s) have adhered to the policies for protection of human subjects as prescribed in 45 CFR 46.

Corresponding author: Brian A. Smoley, MD, MPH, Puget Sound Family Medicine Residency, Department of Family Medicine, Naval Hospital Bremerton, 1 Boone Road, Code 035, Bremerton, Washington 98312 (E-mail: brian.smoley@ med.navy.mil).

\footnotetext{
See Related Commentary on Page 487.
}

mon in the young (prevalence of $8 \%$ in those 18 to 39 years of age). ${ }^{1}$ Compared with the general US population, the US Armed Forces is a young population. For example, $92 \%$ of service members in the US Army from 1995 to 2000 were $<40$ years of age. $^{2}$ Therefore, hypertension should be relatively uncommon in the Armed Forces.

There are additional reasons why hypertension should be less common among US service members. First, hypertension is considered to be disqualifying for entry into the Armed Forces. ${ }^{3}$ Second, service members are required to maintain a minimum standard of physical fitness that would be expected to postpone or prevent the onset of hypertension. ${ }^{4}$ Finally, when hypertension does develop and is complicated or severe, it is a condition for which service members can be separated or retired. $^{5}$

Few studies have examined the prevalence of hypertension among service members. Those that have been performed were limited because they used hypertension diagnosis codes and/or pharmaceutical prescription data to measure recognized hypertension but did not include blood pressure measurements to identify unrecognized cases., ${ }^{2,6,7}$ The purpose of this study was to provide an esti- 
mate of the prevalence of hypertension and distribution of blood pressures in a multiethnic population of male and female active duty US service members in a manner accounting for both recognized and unrecognized cases.

\section{Methods}

\section{Selection and Description of Participants}

The I Corps Readiness and Outcomes Wellness Service (ICROWS) at Madigan Army Medical Center conducts health risk assessments on all active duty service members stationed at Fort Lewis in Tacoma, WA. These assessments are performed annually and within 30 days of a deployment from Fort Lewis. After approval by the Institutional Review Board at Madigan Army Medical Center and the Human Subjects Review Committee at the University of Washington in Seattle, WA, we used a retrospective cross-sectional analysis of data that had been collected during these health risk assessments. All active duty service members (including active National Guard and Reserve) aged 17 to 65 years who completed the health risk assessment between January 1, 2004, and December 31, 2004, were included in the study.

\section{Technical Information}

The Health Risk Appraisal survey (DA Form 5675, 1 Feb 92) was administered as a part of the health risk assessment. ${ }^{8,9}$ The survey collected self-reported information on rank, racial/ethnic background, sex, age, height, weight, and use of medicine for high blood pressure. It also included the recording of a single unaveraged blood pressure measurement taken by trained medical personnel at the time of the health risk assessment. Standardized operating procedures stipulated that the subjects' blood pressure measurements were taken with a calibrated automated sphygmomanometer after they had been seated for 5 minutes and at least 30 minutes after they had last smoked, exercised, or ingested caffeine. ${ }^{10}$ If the blood pressure was $\geq 140 / 90 \mathrm{~mm} \mathrm{Hg}$, a second reading was taken using the same instrument. An automated reading of $<140 / 90 \mathrm{~mm} \mathrm{Hg}$ was recorded. Persistently elevated automated measurements prompted manual measurements in both arms. The higher of the 2 manual measurements was then recorded.

\section{Analyses}

Subjects were defined as having hypertension if their systolic blood pressure was at least $140 \mathrm{~mm}$ $\mathrm{Hg}$, their diastolic blood pressure was at least 90 $\mathrm{mm} \mathrm{Hg}$, or they had reported taking medicine for high blood pressure. Hypertension was considered to be treated if subjects reported using a medicine for high blood pressure. Classification into specific blood pressure categories was based on recorded blood pressures using criteria established in the Seventh Report of the Joint National Committee on Prevention, Detection, Evaluation and Treatment of High Blood Pressure (JNC 7) (ie, normal: $<120 / 80 \mathrm{~mm} \mathrm{Hg}$, prehypertension: 120-139/ 80-89 mm Hg, stage 1 hypertension: 140-159/ 90-99 mm Hg, and stage 2 hypertension: $\geq 160 /$ $100 \mathrm{~mm} \mathrm{Hg}) .{ }^{11}$

Subjects' reported rank was used as a marker for socioeconomic status. Although rank is related to both education level and income, the relationships are not linear across the entire rank structure. Rank was thus dichotomized into the 2 socioeconomic groups of Junior Enlisted (E-1 to E-4) and Senior Rank [all others: senior enlisted (E-5 to E-9), warrant officers (WO-1 to WO-4), and commissioned officers (O-1 to O-10)] in a manner consistent with a previous analysis. ${ }^{12}$ The 8 racial/ethnic background categories from the Health Risk Appraisal survey were collapsed into 4 categories to facilitate statistical analysis and maintain consistency with other categorization schemes. ${ }^{1,2,13}$ Subjects who identified a background of white Hispanic or black Hispanic were categorized as Hispanic. Those who identified a background of American Indian or Alaska native, Asian/Oriental, Pacific Islander, or other were categorized as other. Those who identified themselves as non-Hispanic white or nonHispanic black were categorized as white and black, respectively. Age was categorized into 3 groups (17 to 24,25 to 39 , and 40 to 65 years). Body mass index was calculated by dividing the weight (in kilograms) by the square of the height (in meters).

Statistical analyses were performed using SPSS software. ${ }^{14}$ The prevalence of hypertension by age groups, sex, race/ethnicity, and rank was tested by $\chi^{2}$ and $\chi^{2}$ for trend tests. Multivariate logistic regression models were used to test for independent associations between study subject characteristics (age, body mass index, race/ethnicity, rank, and sex) and hypertension and prehypertension. Age adjustments of prevalence to the 2000 US Standard Pop- 
Table 1. Characteristics of Active Duty Service Members Stationed at Fort Lewis Who Completed the Health Risk Assessment Between January 1, 2004, and December 31, 2004

\begin{tabular}{|c|c|c|c|c|}
\hline \multirow[b]{2}{*}{ Characteristic } & \multicolumn{4}{|c|}{ Age Group (years) } \\
\hline & 17 to $24(\mathrm{n}=7105)$ & 25 to $39(\mathrm{n}=6677)$ & 40 to $65(\mathrm{n}=1609)$ & All $(\mathrm{n}=15,391)$ \\
\hline Mean age [years (SD)] & $21.1(1.9)$ & $30.7(4.3)$ & $45.0(4.6)$ & $27.8(8.2)$ \\
\hline Mean systolic blood pressure $[\mathrm{mm} \mathrm{Hg}(\mathrm{SD})]$ & $124.7(11.4)$ & $128.4(11.5)$ & $130.6(12.8)$ & $126.9(11.7)$ \\
\hline $\begin{array}{l}\text { Mean diastolic blood pressure }[\mathrm{mm} \mathrm{Hg} \\
(\mathrm{SD})]\end{array}$ & $65.2(8.7)$ & $71.5(9.4)$ & $76.6(9.9)$ & $69.1(9.9)$ \\
\hline Mean body mass index $\left[\mathrm{kg} / \mathrm{m}^{2}(\mathrm{SD})\right]$ & $24.4(3.2)$ & $26.3(3.5)$ & $27.0(3.6)$ & $25.5(3.5)$ \\
\hline Medicine for hypertension (\%) & $22(0.3)$ & $102(1.5)$ & $161(10.0)$ & $285(1.9)$ \\
\hline Women (\%) & $981(13.8)$ & $740(11.1)$ & $182(11.3)$ & $1903(12.4)$ \\
\hline \multicolumn{5}{|l|}{ Race/ethnicity (\%) } \\
\hline White & $4189(59.0)$ & $3794(56.8)$ & $900(55.9)$ & $8883(57.7)$ \\
\hline Black & $677(9.5)$ & $878(13.1)$ & $221(13.7)$ & $1776(11.5)$ \\
\hline Hispanic & $1185(16.7)$ & $1027(15.4)$ & $255(15.8)$ & $2467(16.0)$ \\
\hline Other & $1054(14.8)$ & 978 (14.6) & $233(14.5)$ & $2265(14.7)$ \\
\hline \multicolumn{5}{|l|}{ Rank (\%) } \\
\hline Junior enlisted & $6115(86.1)$ & $2244(33.6)$ & $123(7.6)$ & $8482(55.1)$ \\
\hline Senior rank & $990(13.9)$ & $4433(66.4)$ & $1486(92.4)$ & 6909 (44.9) \\
\hline
\end{tabular}

SD, standard deviation.

ulation used a population age range of 18 to 59 years broken down into 10-year increments. ${ }^{15}$ The sensitivity of the prevalence of hypertension and prehypertension to a transient increase in subjects' blood pressures (possibly reflecting a white coatlike effect) at the time of measurement was tested by reducing the values of recorded blood pressures in those with pre- and stage 1 hypertensive readings by $7 / 4 \mathrm{~mm} \mathrm{Hg}$ (the approximate value of the white coat effect in stage 1 hypertensives). ${ }^{16}$

\section{Results}

15,391 of 15,735 eligible service members (98\%) met inclusion criteria. Those excluded included 323 who were missing a blood pressure measurement, 19 who were missing a demographic variable, and 2 who were outside of the study's age range. Population characteristics are presented in Table 1. The mean age in the study population was 28 years, the mean blood pressure was $127 / 69 \mathrm{~mm} \mathrm{Hg}$, and the mean body mass index was $25.5 \mathrm{~kg} / \mathrm{m}^{2}$. Two percent of subjects reported using medicine for high blood pressure. The majority were males and $<40$ years of age. The race/ethnicity group "Hispanic" included 2050 subjects $(83 \%)$ who more specifically identified themselves as white Hispanic and $417(17 \%)$ who identified themselves as black Hispanic. The race/ethnicity group "other" included 290 American Indians or Alaska natives
(13\%), 704 Asians/Orientals (31\%), and 378 Pacific Islanders (17\%).

The prevalence of hypertension (as defined for this study) was $13 \%$ overall and $11 \%$ in those $<40$ years of age (Table 2). Hypertension was more common in older age groups, men, blacks, and those in the senior ranks. The age-adjusted prevalence of hypertension was $21 \%$ for men and $15 \%$ for women. Hypertension was treated in 285 (15\%) of all cases, $124(8 \%)$ of cases in subjects $<40$ years of age, and $161(37 \%)$ of cases in subjects 40 to 65 years of age, yielding treated hypertension prevalences of $2 \%$ overall, $1 \%$ in those $<40$ years of age, and $10 \%$ in those 40 to 65 years of age.

Multivariate logistic regression showed age, body mass index, male sex, black race/ethnicity, and senior rank to be independently associated with an increased odds of having hypertension (Table 3). Rank and age were noted to be only moderately correlated with each other (Spearman's rank coefficient $=0.65$ ).

The distribution of blood pressures for the 15,106 subjects who did not report taking medicine for high blood pressure is shown in Table 4. Prehypertension was the most prevalent blood pressure category (63\%), followed by normal blood pressure (26\%) and then stage 1 and stage 2 hypertension (10\% and $1 \%$, respectively). Multivariate logistic regression showed prehypertension to be 
Table 2. Prevalence of Hypertension by Age Group Among Active Duty Service Members Stationed at Fort Lewis

\begin{tabular}{|c|c|c|c|c|c|}
\hline \multirow[b]{2}{*}{ Characteristic } & \multicolumn{5}{|c|}{ Age Group (Years) } \\
\hline & 17 to 24 & 25 to 39 & 40 to 65 & All & $P^{*}$ \\
\hline Overall (\%) & $560(7.9)$ & $966(14.5)$ & $438(27.2)$ & $1964(12.8)$ & $<.01$ \\
\hline \multicolumn{6}{|l|}{ Sex $(\%)$} \\
\hline Men & $534(8.7)$ & $914(15.4)$ & $395(27.7)$ & $1843(13.7)$ & $<.01$ \\
\hline Women & $26(2.7)$ & $52(7.0)$ & $43(23.6)$ & $121(6.4)$ & $<.01$ \\
\hline$P^{\dagger}$ & $<.01$ & $<.01$ & .25 & $<.01$ & \\
\hline \multicolumn{6}{|l|}{ Race/ethnicity (\%) } \\
\hline White & $357(8.5)$ & $516(13.6)$ & $227(25.2)$ & $1100(12.4)$ & $<.01$ \\
\hline Black & $63(9.3)$ & $176(20.0)$ & $75(33.9)$ & $314(17.7)$ & $<.01$ \\
\hline Hispanic & $74(6.2)$ & $128(12.5)$ & $79(31.0)$ & $281(11.4)$ & $<.01$ \\
\hline Other & $66(6.3)$ & $146(14.9)$ & $57(24.5)$ & $269(11.9)$ & $<.01$ \\
\hline$P^{\dagger}$ & .01 & $<.01$ & .02 & $<.01$ & \\
\hline \multicolumn{6}{|l|}{ Rank (\%) } \\
\hline Junior enlisted & $453(7.4)$ & $264(11.8)$ & $35(28.5)$ & $752(8.9)$ & $<.01$ \\
\hline Senior rank & $107(10.8)$ & $702(15.8)$ & $403(27.1)$ & $1212(17.5)$ & $<.01$ \\
\hline$P^{\dagger}$ & $<.01$ & $<.01$ & .75 & $<.01$ & \\
\hline
\end{tabular}

${ }^{\dagger} \chi^{2}$ comparisons within age groups.

${ }^{*} \chi^{2}$ test for trend across age categories.

independently associated with body mass index, male sex, and senior rank $(P$ values $<.01,<.01$, and .01 , respectively) but not age or race/ethnicity. Viewed as a portion of the entire study population, the 9560 of these subjects with prehypertensive blood pressure readings represent an unadjusted prevalence of prehypertension of $62 \%$ (64\% in men and $47 \%$ in women). Adjusted for age, the prevalence of prehypertension was $62 \%$ for men and $48 \%$ for women.

A sensitivity analysis that decreased the observed blood pressure readings in those with pre- and stage 1 hypertensive readings by $7 / 4 \mathrm{~mm} \mathrm{Hg}$ esti-

Table 3. Associations Between Hypertension and Study Subject Characteristics

\begin{tabular}{lc}
\hline Characteristic & OR $(95 \% \text { CI })^{*}$ \\
\hline Age (per 1-year increase) & $1.04(1.04$ to 1.05$)$ \\
Body mass index (per $\mathrm{kg} / \mathrm{m}^{2}$ increase) & $1.13(1.12$ to 1.15$)$ \\
Male & $1.96(1.61$ to 2.39$)$ \\
Race/ethnicity & \\
White & 1.00 (reference) \\
Black & $1.52(1.31$ to 1.75$)$ \\
Hispanic & $0.87(0.75$ to 1.00$)$ \\
Other & $0.99(0.85$ to 1.14$)$ \\
Senior rank & $1.23(1.09$ to 1.39$)$ \\
\hline
\end{tabular}

*Odds ratio (OR) (95\% CI) simultaneously adjusted for all characteristics. mated the prevalence of hypertension and prehypertension after the removal of the white coat effect to be $6 \%$ and $48 \%$, respectively (not age adjusted).

\section{Discussion}

With an overall prevalence of $13 \%$ and $62 \%$, and a combined prevalence of $75 \%$, hypertension and prehypertension were more common in our study than has been previously described in a military population. Our analysis is the first to provide an estimate of the prevalence of hypertension and a description of the distribution of blood pressure categories in a large population of US service members that is based primarily on recorded blood pressure readings. Earlier studies differed from our investigation in that they were designed to detect only recognized cases. One group of researchers at a Department of Defense medical treatment facility (MTF) used pharmacy records to estimate the prevalence of treated hypertension at $1.5 \%$ in their entire population, $0.8 \%$ in those $<40$ years of age, and $10.0 \%$ in those $>40$ years of age. ${ }^{6}$ Another group used the pharmacy and ambulatory data system records of a population of 40- to 89-year-old medical beneficiaries receiving care at a different MTF to estimate the prevalence of diagnosed hypertension to be $12.3 \% .^{7}$ An investigation of the entire US Army population revealed a prevalence 
Table 4. Blood Pressure Categories Among Active Duty Service Members (Fort Lewis) Not Taking Medicine for High Blood Pressure

\begin{tabular}{|c|c|c|c|c|}
\hline \multirow[b]{2}{*}{ Characteristic } & \multicolumn{4}{|c|}{ Blood Pressure Category } \\
\hline & Normal & Prehypertension & Stage 1 Hypertension & Stage 2 Hypertension \\
\hline Overall & $\mathrm{n}=3867$ & $\mathrm{n}=9560$ & $\mathrm{n}=1535$ & $\mathrm{n}=144$ \\
\hline \multicolumn{5}{|l|}{ Age groups (\%) } \\
\hline 17 to 24 years & $2271(32.1)$ & $4274(60.3)$ & $508(7.2)$ & $30(0.4)$ \\
\hline 25 to 39 years & $1339(20.4)$ & $4372(66.5)$ & $787(12.0)$ & $77(1.2)$ \\
\hline 40 to 65 years & $257(17.7)$ & $914(63.1)$ & $240(16.6)$ & $37(2.6)$ \\
\hline \multicolumn{5}{|l|}{ Sex $(\%)$} \\
\hline Men & $2988(22.6)$ & $8657(65.4)$ & $1453(11.0)$ & $134(1.0)$ \\
\hline Women & $879(46.9)$ & $903(48.2)$ & $82(4.4)$ & $10(0.5)$ \\
\hline \multicolumn{5}{|l|}{ Race/ethnicity (\%) } \\
\hline White & $2241(25.6)$ & $5542(63.4)$ & $888(10.2)$ & $71(0.8)$ \\
\hline Black & $404(23.8)$ & $1058(62.2)$ & $207(12.2)$ & $31(1.8)$ \\
\hline Hispanic & $631(25.9)$ & $1555(63.9)$ & $226(9.3)$ & $20(0.8)$ \\
\hline Other & $591(26.5)$ & $1405(62.9)$ & $214(9.6)$ & $22(1.0)$ \\
\hline \multicolumn{5}{|l|}{ Rank (\%) } \\
\hline Junior enlisted & $2548(30.2)$ & $5182(61.5)$ & $647(7.7)$ & $54(0.6)$ \\
\hline Senior rank & $1319(19.8)$ & $4378(65.6)$ & $888(13.3)$ & $90(1.3)$ \\
\hline
\end{tabular}

of diagnosed hypertension of $2 \%$ overall, $1 \%$ to $2 \%$ in 17 - to 39 -year-olds, $7 \%$ in 40 - to 65 -year-old men, and $8 \%$ in 40 - to 65 -year-old women. ${ }^{2}$ All these findings are similar to the prevalence of treated hypertension in our study population ( $2 \%$ overall, $1 \%$ in 17 - to 39 -year-olds, and $10 \%$ in 40 to 65 -year-olds). However, the results of our study suggest that the prevalence of all hypertension in US military populations is higher than what is reflected in the records of diagnoses or prescribed medications.

National surveys using measured blood pressures have yielded age-adjusted estimates of hypertension prevalence of $27 \%$ in men and $30 \%$ in women. ${ }^{17}$ The age-adjusted prevalence in our study population was $21 \%$ in men and $15 \%$ in women. Although probably more prevalent than previously reported, it seems as though hypertension is still less prevalent in the US Armed Forces than it is in the general US population. In contrast, prehypertension was more prevalent in our study population (age-adjusted prevalence of $62 \%$ for men and $48 \%$ for women) than has been estimated in the general US population (age-adjusted prevalence of $47 \%$ in men and $29 \%$ in women). ${ }^{18}$ Although prehypertension was associated with body mass index (BMI), adjusting for the lower BMI found in our study population [mean BMI of $25.5 \mathrm{~kg} / \mathrm{m}^{2}$ (Table 1) vs $27.8 \mathrm{~kg} / \mathrm{m}^{2}$ (see ref. ${ }^{17}$ )] would increase the preva- lence in our study population relative to the US population, and therefore does not explain the higher prevalence of prehypertension.

It is therefore important to consider what biases might have been introduced as a result of the methods used by the ICROWS to collect the blood pressure data. The health risk assessments conducted on the study subjects included the recording of only one blood pressure measurement. As a comparison, JNC 7 and National Health and Nutrition Examination Survey (NHANES) procedures characterize individuals based on at least 2 measurements. ${ }^{11,19,20}$ It has been shown that the classification of individuals based on even just 2 measurements can lead to a significant overdiagnosis of hypertension. ${ }^{21-23}$ Classification based on one measurement would be expected to be at least as inaccurate.

A more significant source of error in this study, and the one that best explains any artificial inflation of the prevalence of prehypertension relative to national surveys, is the bias that was probably introduced by the selective recording of one out of as many as 4 blood pressure measurements that could have been taken during the subjects' health risk assessments. There is a statistical tendency for extreme blood pressure readings to "regress toward the mean" such that repeat measurements in initially hypertensive individuals would generally be 
expected to be lower. ${ }^{24,25}$ Because blood pressure measurements were only repeated in those subjects who were initially hypertensive, a selection bias toward pre- and normotensive blood pressure values may have been introduced. This bias would have had the effect of increasing the observed prevalence of prehypertension while simultaneously decreasing the observed prevalence of hypertension.

It is also possible that there was something about the service members or the setting of the health risk assessment that introduced error through an artificial inflation of the measured blood pressures. The United States was engaged in active combat operations at the time that the data were collected. The annual health risk appraisal was completed in preparation for combat deployments for some of the individuals in the study. It is possible that some subjects completing the health risk appraisal during this time may have experienced some sort of "alarm reaction" similar to the one that has been found to occur in some patients during physician visits. ${ }^{26,27}$ This "alarm reaction" manifests as a transient increase in blood pressure and has been termed the "white coat effect." 28,29 Although its magnitude increases with the severity of hypertension, the impact of the white coat effect on the measured prevalence of hypertension is most pronounced in those with mild (ie, stage 1 ) disease. ${ }^{16}$ Because no estimation of the magnitude of the white coat effect in prehypertensives has been reported, the value reported for stage 1 hypertensives was conservatively applied to all pre- and stage 1 hypertensive readings in the sensitivity analysis. The prevalence of hypertension and prehypertension were both found to be sensitive to this adjustment (6\% vs $13 \%$ for hypertension and $48 \%$ vs $62 \%$ for prehypertension), although prehypertension remained significantly prevalent.

The retrospective nature of our investigation has introduced a number of biases that may have lead to the overestimation of the prevalence of hypertensive disease in the study population. However, 2 of these biases had competing effects, and although accounting for a white coat-like effect decreased the observed prevalence, it did not normalize it. Therefore, our results nonetheless suggest that hypertension is more common in the military population than has been previously appreciated and that prehypertension may actually be more common than in the general US population.
The implications of this finding warrant careful consideration. Several studies have found prehypertension to be associated with an increased risk of developing overt hypertension, but most of these studies have been done in older populations. ${ }^{30-32}$ Two cohort studies that included younger subjects followed for as long as 8 years found that even young adults with prehypertension have an increased risk of developing hypertension. ${ }^{33,34}$ However, they may not face the same elevated risk of cardiovascular morbidity and mortality as has been found in older prehypertensives. ${ }^{30,35-37}$ The $\mathrm{Na}$ tional Health Examination and Follow-up Study and NHANES II Mortality Study, 1992 provided up to 18 years of follow-up for large cohorts that included adults as young as 25 years of age at enrollment. Whereas the former demonstrated a 1.32 -fold (95\% CI, 1.05 to 1.65 ) increase in the risk of cardiovascular events in prehypertensive subjects, the latter revealed no significant increase in the risk of either all-cause or cardiovascular-related mortality that could be attributed to baseline prehypertension. ${ }^{38,39}$

JNC 7 recommendations for the treatment of prehypertension in an average risk patient of any age are limited to lifestyle modifications, ${ }^{11}$ but the utility of this approach is debatable, particularly when considering a young population like the US Armed Forces. Lifestyle modifications are recommended because of their positive effect on blood pressure, incident hypertension, antihypertensive efficacy, and cardiovascular risk. ${ }^{11}$ One follow-up study has shown that dietary sodium reduction is associated with a decreased risk of cardiovascular disease over a period of 10 to 15 years. ${ }^{40}$ However, these results may not be reproducible in nonstudy settings, and the long-term effects of other lifestyle modifications on cardiovascular events have not been clearly established. ${ }^{41}$ Even if they were, the absolute cardiovascular risk for most young adults is already low, even in prehypertensives. This is not to say that prehypertension should be ignored in this demographic. Although their risk may be low while they are still young, they will age, at which point their risk for both hypertension and cardiovascular morbidity and mortality will increase. Although direct evidence for lifestyle changes in young adulthood may be lacking, it nonetheless seems appropriate to address them at this earlier time rather than waiting until later in life when a lifetime of destructive habits added to age and hy- 
pertensive disease has raised cardiovascular risk to the point where treatment is no longer a consideration, but rather a mandate.

Given the limitations imposed in our retrospective analysis of a previously collected database, the prevalence of hypertensive disease in the military population should be confirmed by prospective studies that use multiple blood pressure measurements as has been done in NHANES. ${ }^{19}$ Such studies should also assess service members' dietary, smoking, and alcohol consumption habits to determine the feasibility and potential impact of lifestyle changes on blood pressure readings in this already lean and physically active population. These will set the stage for prospective assessments of the longterm benefits to be gained from the identification and treatment of hypertension and prehypertension in early adulthood. Until then, service members need to be educated and motivated to adopt healthy lifestyles, if not to decrease their cardiovascular risk now, then to decrease it in the future.

\section{References}

1. Wang Y, Wang QJ. The prevalence of prehypertension and hypertension among US adults according to the new joint national committee guidelines: new challenges of the old problem. Archives Intern Med 2004;164:2126-34.

2. Pfizer. The health status of the United States Army: findings from the Total Army Injury and Health Outcomes Database (TAIHOD). New York: Pfizer Inc.; 2003.

3. Department of Defense Instruction 6130.4: “Criteria and Procedure Requirements for Physical Standards for Appointment, Enlistment, or Induction in the Armed Forces." Washington (DC): U.S. Department of Defense; 2004.

4. Department of Defense Directive 1308.1, "DoD Physical Fitness and Body Fat Program." Washington (DC): U.S. Department of Defense; 2004.

5. Department of Defense Instruction 1332.38, "Separation or Retirement for Physical Disability." Washington (DC): U.S. Department of Defense; 1996.

6. Hennessy BJ, Kerns DG, Davies WG. The incidence of active duty dental patients taking antihypertensive medications. Mil Med 1999;164:740-5.

7. Johnson BW, Davies WG, Hardy DW, et al. A descriptive analysis of hypertension and affiliated therapies in a military retiree population (ages 40-85 years) at Camp Lejeune. North Carolina. Mil Med 2003;168:424-5.

8. Army Regulation 40-501, "Standards of Medical Fitness." Washington (DC): U.S. Department of the Army; 1998.
9. Army Regulation 600-63, "Army Health Promotion." Washington (DC): U.S. Department of the Army; 1996.

10. VA/DoD Evidence-Based Clinical Practice Guideline Working Group, Veterans Health Administration, Department of Veterans Affairs, and Health Affairs, Department of Defense. Diagnosis and Management of Hypertension in the Primary Care Setting. Washington (DC): Office of Quality and Performance; 1999, 2004 (update).

11. Chobanian AV, Bakris GL, Black HR, et al. Seventh report of the Joint National Committee on Prevention. Detection, evaluation, and treatment of high blood pressure. Hypertension 2003;42:1206-52.

12. Kugler JP, Yeash J, Rumbaugh PC. The impact of sociodemographic, health care system, and family function variables on prenatal care utilization in a military setting. J Fam Pract 1993;37:143-7.

13. Department of the Army. Army demographics FY00. Washington (DC): U.S. Department of the Army; 2000.

14. SPSS 12.0.2 for Windows. Chicago: SPSS Inc.; 1989-2003.

15. Klein RJ, Schoenborn CA. Age adjustment using the 2000 projected U.S. population. Healthy People 2010 Stat Notes. 2001 Jan(20):1-10.

16. Verdecchia P, Schillaci G, Borgioni C, et al. White coat hypertension and white coat effect. Similarities and differences. Am J Hypertens 1995;8:790-8.

17. Hajjar I, Kotchen TA. Trends in prevalence, awareness, treatment, and control of hypertension in the United States, 1988-2000. JAMA 2003;290:199-206.

18. Qureshi AI, Suri MF, Kirmani JF, Divani AA. Prevalence and trends of prehypertension and hypertension in United States: National Health and Nutrition Examination Surveys 1976 to 2000. Med Sci Monit 2005;11:CR403-9.

19. Plan and operation of the Third National Health and Nutrition Examination Survey, 1988-94. Series 1: programs and collection procedures. Vital Health Stat 1 1994;Jul(32):1-407.

20. National Health and Nutrition Examination Survey Physician Examination Procedures Manual. Hyattsville (MD): National Center for Health Statistics; 1999 [updated 2000; cited 2006 December 30]. Available from: http://www.cdc.gov/nchs/about/major/nhanes/ currentnhanes.htm.

21. Marshall T. Misleading measurements: modeling the effects of blood pressure misclassification in a United States population. Med Decis Making 2006;26:62432.

22. Perry HM, Jr, Miller JP. Difficulties in diagnosing hypertension: implications and alternatives. J Hypertens 1992;10:887-96.

23. Turner MJ, van Schalkwyk JM. Blood pressure variability causes spurious identification of hypertension in clinical studies: a computer simulation study. Am J Hypertens 2008;21:85-91. 
24. Bland JM, Altman DG. Regression towards the mean. BMJ 1994;308:1499.

25. Bland JM, Altman DG. Some examples of regression towards the mean. BMJ 1994;309:780.

26. Mancia G, Bertinieri G, Grassi G, et al. Effects of blood-pressure measurement by the doctor on patient's blood pressure and heart rate. Lancet 1983;2: 695-8.

27. Mancia G, Parati G, Pomidossi G, Grassi G, Casadei $\mathrm{R}$, Zanchetti A. Alerting reaction and rise in blood pressure during measurement by physician and nurse. Hypertension 1987;9:209-15.

28. Pickering TG, James GD, Boddie C, Harshfield GA, Blank S, Laragh JH. How common is white coat hypertension? JAMA 1988;259:225-8.

29. Parati G, Mancia G. White coat effect: semantics, assessment and pathophysiological implications. J Hypertens 2003;21:481-6.

30. Qureshi AI, Suri MF, Kirmani JF, Divani AA, Mohammad Y. Is prehypertension a risk factor for cardiovascular diseases? Stroke 2005;36:1859-63.

31. Vasan RS, Larson MG, Leip EP, Kannel WB, Levy D. Assessment of frequency of progression to hypertension in non-hypertensive participants in the Framingham Heart Study: a cohort study. Lancet 2001; 358:1682-6.

32. Winegarden CR. From "prehypertension" to hypertension? Additional evidence. Ann Epidemiol 2005; 15:720-5.

33. Chiu YH, Wu SC, Tseng CD, Yen MF, Chen TH. Progression of pre-hypertension, stage 1 and 2 hypertension (JNC 7): a population-based study in Keelung.
Taiwan (Keelung Community-based Integrated Screening No. 9). J Hypertens 2006;24:821-8.

34. Zhang H, Thijs L, Kuznetsova T, Fagard RH, Li X, Staessen JA. Progression to hypertension in the nonhypertensive participants in the Flemish Study on Environment, Genes and Health Outcomes. J Hypertens 2006;24:1719-27.

35. Lewington S, Clarke R, Qizilbash N, Peto R, Collins R. Age-specific relevance of usual blood pressure to vascular mortality: a meta-analysis of individual data for one million adults in 61 prospective studies. Lancet 2002;360:1903-13.

36. Lloyd-Jones DM, Evans JC, Levy D. Hypertension in adults across the age spectrum: current outcomes and control in the community. JAMA 2005;294:46672.

37. Vasan RS, Larson MG, Leip EP, et al. Impact of high-normal blood pressure on the risk of cardiovascular disease. New Engl J Med 2001;345:1291-7.

38. Liszka HA, Mainous AG, 3rd, King DE, Everett CJ, Egan BM. Prehypertension and cardiovascular morbidity. Ann Fam Med 2005;3:294-9.

39. Mainous AG, 3rd, Everett CJ, Liszka H, King DE, Egan BM. Prehypertension and mortality in a nationally representative cohort. Am J Cardiol 2004; 94:1496-500.

40. Cook NR, Cutler JA, Obarzanek E, et al. Long term effects of dietary sodium reduction on cardiovascular disease outcomes: observational follow-up of the trials of hypertension prevention (TOHP). BMJ 2007; 334:885

41. Elliott WJ, Black HR. Prehypertension. Nat Clin Pract Cardiovasc Med 2007;4:538-48. 